\title{
Clinical and Cost Implications of Insulin Degludec in Patients with Type 1 Diabetes and Problematic Hypoglycemia: A Quality Improvement Project
}

\author{
Muhammad Ali Karamat (D) Shujah Dar - Srikanth Bellary • \\ Abd A. Tahrani
}

Received: January 23, 2018 / Published online: March 16, 2018

(C) The Author(s) 2018

\begin{abstract}
Introduction: To assess the real-life clinical benefits and cost implications of switching from another basal insulin to insulin degludec (degludec) in patients with type 1 diabetes (T1D) on basal-bolus regimens with recurrent hypoglycemia and/or hypoglycemia unawareness.
\end{abstract}

Enhanced content To view enhanced content for this article go to https://doi.org/10.6084/m9.figshare. 5933110.

M. A. Karamat $(\bowtie) \cdot$ S. Bellary · A. A. Tahrani Department of Diabetes and Endocrinology, Diabetes Centre, Heartlands Hospital, Birmingham, UK

e-mail:

muhammad.karamat@heartofengland.nhs.uk

M. A. Karamat · A. A. Tahrani

Institute of Metabolism and Systems, School of Clinical and Experimental Medicine, University of Birmingham, Birmingham, UK

M. A. Karamat · A. A. Tahrani

Centre of Endocrinology, Diabetes and Metabolism, Birmingham Health Partners, Birmingham, UK

S. Dar

Department of Diabetes and Endocrinology, Queen

Elizabeth Hospital, Birmingham, UK

S. Bellary

School of Life and Health Sciences, Aston

University, Aston Triangle, Birmingham, UK
Methods: Patients with T1D who were aged $\geq 18$ years, were on a basal-bolus regimen, and had switched to degludec plus bolus insulin for at least 6 months were included. Patients had to have switched to degludec as a result of recurrent hypoglycemia and/or hypoglycemia unawareness.

Results: Six months of follow-up data were available for 42 patients. At 6 months, there was a significant reduction in median (interquartile range) $\mathrm{HbA}_{1 \mathrm{c}}$, from 8.6 (8.0-9.3)\% [70 (64-78) $\mathrm{mmol} / \mathrm{mol}]$ to $8.4(7.9-8.9) \%$ [68 (63-74) $\mathrm{mmol} / \mathrm{mol}] ; p<0.05$. Median daily basal insulin dose reduced significantly from 30.0 (14.7-45.0) to $25.5 \quad(14.0-30.2)$ units; $p<0.0001$. Data from hospital records showed reductions in the frequency of episodes of severe hypoglycemia from eight in the 6 months preceding degludec initiation to two in the 6 months following initiation. In the same period, diabetic ketoacidosis (DKA) episodes reduced from two before degludec initiation to no episodes after initiation. No patients reported worsening treatment satisfaction after switching to degludec. Considering the reductions in the basal dose required and the frequency of hypoglycemia episodes, we estimate that switching such patients to degludec from other basal insulins could provide significant savings in direct healthcare costs.

Conclusion: In patients with T1D, switching to degludec was associated with an improvement in $\mathrm{HbA}_{1 \mathrm{c}}$ and reductions in basal insulin dose, 
severe hypoglycemia, and DKA. When used in appropriate patients, degludec could lead to significant cost savings.

Funding: Novo Nordisk.

Keywords: Healthcare delivery; Hypoglycemia; Insulin degludec; Insulin therapy; Type 1 diabetes

\section{INTRODUCTION}

Hypoglycemia in patients with type 1 diabetes (T1D) represents a considerable economic burden to the UK National Health Service (NHS). Data from the West Midlands Ambulance Service show that between January 1, 2013 and December 31, 2014 in the West Midlands region of the UK (covering a population of 5.6 million [1]), there were 3813 ambulance call-outs related to hypoglycemia, costing the NHS over $£ 900,000$ [2]. During the same period, hospital admissions attributed to a primary diagnosis of hypoglycemia were estimated to cost $£ 464,760$ [3]. Hypoglycemia can have considerable negative effects on patient quality-of-life (QoL), with an increased frequency and severity of hypoglycemic episodes associated with greater reductions in QoL [4]. Severe hypoglycemia is associated with an increased risk of falls, fractures, cardiovascular disease, major adverse cardiovascular events, major microvascular events, dementia (in older patients) and death [5-8].

Insulin degludec (degludec) is a long-acting basal insulin with a duration of action extending to over $40 \mathrm{~h}$ in most patients at therapeutic doses [9]. It has a flat pharmacodynamic profile at steady state, with less injection-to-injection variability in glucose-lowering activity than insulin glargine 100 units/mL (glargine U100) $[9,10]$. Randomized controlled trials (RCTs) in patients with T1D and type 2 diabetes (T2D) have shown that, compared with glargine U100, degludec leads to a reduced risk of hypoglycemia, particularly nocturnal hypoglycemia, at equivalent levels of glycemic control across a broad spectrum of patients [11-13]. Degludec has also been associated with improved QoL scores in phase 3 clinical trials compared with glargine U100 in T1D and T2D [14]. RCTs are the gold standard for developing evidence on the safety and efficacy of new treatment options, but their well-known limitations, such as their strictly defined inclusion and exclusion criteria, restrict the generalizability of their results to the more heterogeneous populations of patients encountered in clinical practice [15]. Real-world studies can provide a valuable additional source of evidence that complements clinical trial data and helps to bridge the knowledge gap between RCTs and real-world practice. To date, a small number of non-interventional studies have evaluated the clinical effectiveness and safety of switching to degludec from other basal insulins in real-world clinical practice [16-18]. These studies report improved glycemic control and a reduced risk of hypoglycemia after switching to degludec from regimens involving other basal insulins in patients with T1D or T2D [16-18].

A recent short-term health economic analysis based on data from the phase 3 a registration trials and modeling based on the UK NHS setting found degludec to be dominant (more effective at a lower cost) over glargine U100 in patients with T1D or patients with T2D on basal-only therapy, and cost-effective for T2D and a basal-bolus regimen [19]. Scenario analyses versus two recently marketed basal insulin analogs indicated that degludec would likely be cost-effective versus glargine 300 units/mL and biosimilar glargine across diabetes types and treatment regimens [19]. However, the trials included in this analysis excluded patients with a history of recurrent hypoglycemia and those at a high risk of hypoglycemia, such as patients with hypoglycemic unawareness, where degludec might be particularly beneficial in a clinical setting.

This prospective, real-world study was therefore undertaken to investigate the effects of switching basal insulin to degludec in T1D patients with problematic hypoglycemia, including hypoglycemia unawareness. Study endpoints included changes in glycemic control, basal insulin dose, rates of hypoglycemia, and changes in hypoglycemia unawareness status and QoL. An exploratory analysis of the cost-effectiveness of switching to degludec was also carried out. 


\section{METHODS}

This was a prospective, quality-improvement project in patients with T1D attending the outpatient clinics at the Heart of England NHS Foundation Trust (the Trust) (see Fig. 1 for project design). Data were extracted retrospectively to compare clinical outcomes and QoL in patients with T1D and problematic hypoglycemia who were switched to degludec from regimens that included other basal insulins, as part of routine clinical practice. The audit was registered and the data were collected as part of routine clinical care and subject to the Trust's usual governance regulations. Patients were included in the study if they:

- Had T1D and attended the outpatient clinics at the Trust;

- Were aged $\geq 18$ years;

- Were on an insulin regimen comprising either a basal-bolus regimen or biphasic insulin, and

- Had one or more of the following:

- Recurrent severe or nocturnal hypoglycemia

- Documented hypoglycemia unawareness, as identified from the patients' blood glucose (BG) diaries and/or data from a continuous glucose monitor.

All eligible patients were reviewed by a physician and offered the option of switching their basal insulin or biphasic insulin after excluding all other reasonable options to improve control, such as changing the timing of the basal insulin injections and splitting the dose between more than one daily injection. All patients had also received structured diabetes education, such as the Bournemouth Type 1 Diabetes Education Programme, well before commencing treatment with degludec, as part of routine clinical practice for patients with T1D. No education programs were initiated as part of the treatment switch. Eligible patients were then switched to degludec and any previous basal/biphasic insulins were discontinued. Patients were advised to take degludec administered daily in the morning, initiated with a $20 \%$ dose reduction from the previous basal insulin dose. Doses were subsequently titrated as required. Bolus insulin was administered at mealtimes. All patients were followed up for a period of 6 months.

Demographic details, $\mathrm{HbA}_{1 \mathrm{c}}$ levels, previous basal insulin dose, previous episodes of diabetic ketoacidosis (DKA), and episodes of hypoglycemia [defined as $\mathrm{BG} \leq 70.3 \mathrm{mg} / \mathrm{dL}$ $(3.9 \mathrm{mmol} / \mathrm{L})]$ were recorded for all patients for 6 months before and for 6 months after the initiation of degludec. Episodes of hypoglycemia were recorded via home BG monitoring or continuous glucose monitoring systems (for a subset of patients) and recorded in patients' BG diaries. Data on the number of episodes of DKA and ambulance call-outs for 6 months before and 6 months after starting degludec were obtained from hospital records.

At degludec initiation and at the 6-month follow-up, patients completed a diabetes questionnaire based on the Clarke Hypoglycemia Questionnaire as part of routine clinical care for

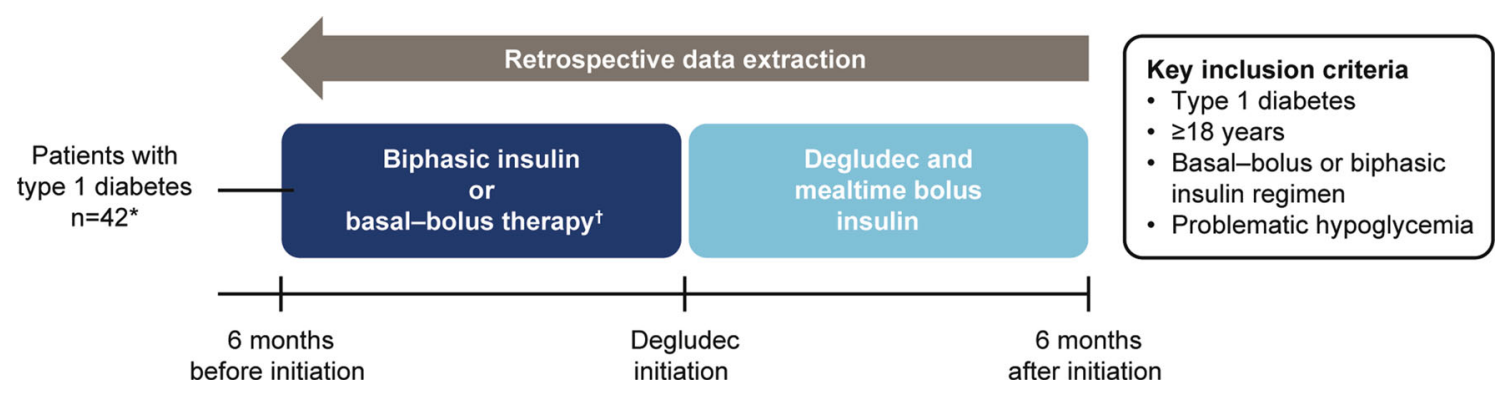

Fig. 1 Quality improvement project design. Asterisk indicates a total of 45 patients were included in the project, three of whom discontinued degludec and initiated

continuous subcutaneous insulin infusion at the physician's discretion; Dagger symbol indicates excluding regimens with degludec 
patients with T1D and problematic hypoglycemia [20]. This is a self-reported measure of the number of episodes of hypoglycemia and of the extent that patients experienced hypoglycemia unawareness. At the 6-month followup, patients completed a satisfaction questionnaire, which included questions about fear of hypoglycemia, confidence in efficacy of treatment, predictability of BG readings, concerns over diabetes, treatment satisfaction, and whether the patient was happy to continue treatment.

\section{Statistical Analysis}

Paired-sample $t$ tests were carried out to compare changes in $\mathrm{HbA}_{1 \mathrm{c}}$ at baseline and at the 6-month follow-up. A related-sample Wilcoxon signed-rank test was used to compare basal doses at baseline (before the switch to degludec) and at the 6-month follow-up. Missing data were dealt with using list-wise deletion.

An exploratory cost-effectiveness analysis was performed to provide an illustrative example of the costs associated with switching to degludec from other basal insulins in patients with T1D and problematic hypoglycemia as part of routine clinical practice. For the purposes of this cost analysis, severe hypoglycemia was defined as an episode requiring an ambulance call-out and/or hospital admission. Data from hospital records and the West Midlands Ambulance Service were used to estimate the change in the number of severe hypoglycemic events experienced in the 6-month period before and after switching to degludec. These data and basal insulin costs (taken as glargine U100 for the pre-switch arm) based on UK list prices [21] were used to estimate any cost savings [in pounds sterling (GBP), based on 2016 costs and values] caused by patients switching to degludec (due to reductions in the number of severe hypoglycemic events and the basal insulin dose); see Fig. 2 for an overview of the cost-effectiveness model. The average annual change in cost per patient attributable to the reduced incidence of severe hypoglycemia upon switching to degludec was offset against the difference in the average annual insulin treatment costs, accounting for any change in dose requirement.

\section{Compliance with Ethics Guidelines}

This article is based on previously conducted studies and does not contain any studies with human participants or animals performed by any of the authors.

\section{RESULTS}

\section{Baseline Characteristics}

A total of 45 patients were initially approached to be included in the study, but three patients discontinued degludec and were switched to continuous subcutaneous insulin infusion, at their physician's discretion. Therefore, 42 patients met the inclusion criteria and provided data. Demographic and clinical characteristics of the cohort are shown in Table 1. Degludec dose values at initiation were missing for four patients; degludec dose values at follow-up were missing for eight patients; $\mathrm{HbA}_{1 \mathrm{c}}$ values at follow-up were missing for four patients. Some of this missing information was the result of failure to attend the 6-month follow-up clinic appointments. At the beginning of the study, the basal insulins given to the patients were glargine U100 (Lantus ${ }^{\circledR}$, Sanofi-Aventis US LLC, Bridgewater, NJ, USA; $n=23$ ); insulin detemir (Levemir $^{\circledR}$, Novo Nordisk A/S; $n=17$ ); biphasic insulin lispro (Humalog ${ }^{\circledR}$ Mix $25^{\circledR}$, Eli Lilly Nederland B.V., Utrecht, The Netherlands; $n=1$; Novomix 30, $n=1$ ); or Insulatard ${ }^{\circledR}$ (Novo Nordisk A/S; $n=1)$. At degludec initiation, 31 (74\%) patients were experiencing disabling and/ or recurrent nocturnal hypoglycemia and 11 (26\%) had hypoglycemia unawareness.

\section{Endpoints}

At the 6-month follow-up, there was a significant reduction in mean (standard deviation) $\mathrm{HbA}_{1 \mathrm{c}}$ from 8.7 (1.3) \% [72 (14) $\left.\mathrm{mmol} / \mathrm{mol}\right]$ to $8.4(1.1) \%$ [68 (12) $\mathrm{mol} / \mathrm{mol}] ; p<0.05$. Median (interquartile range) daily basal insulin dose 


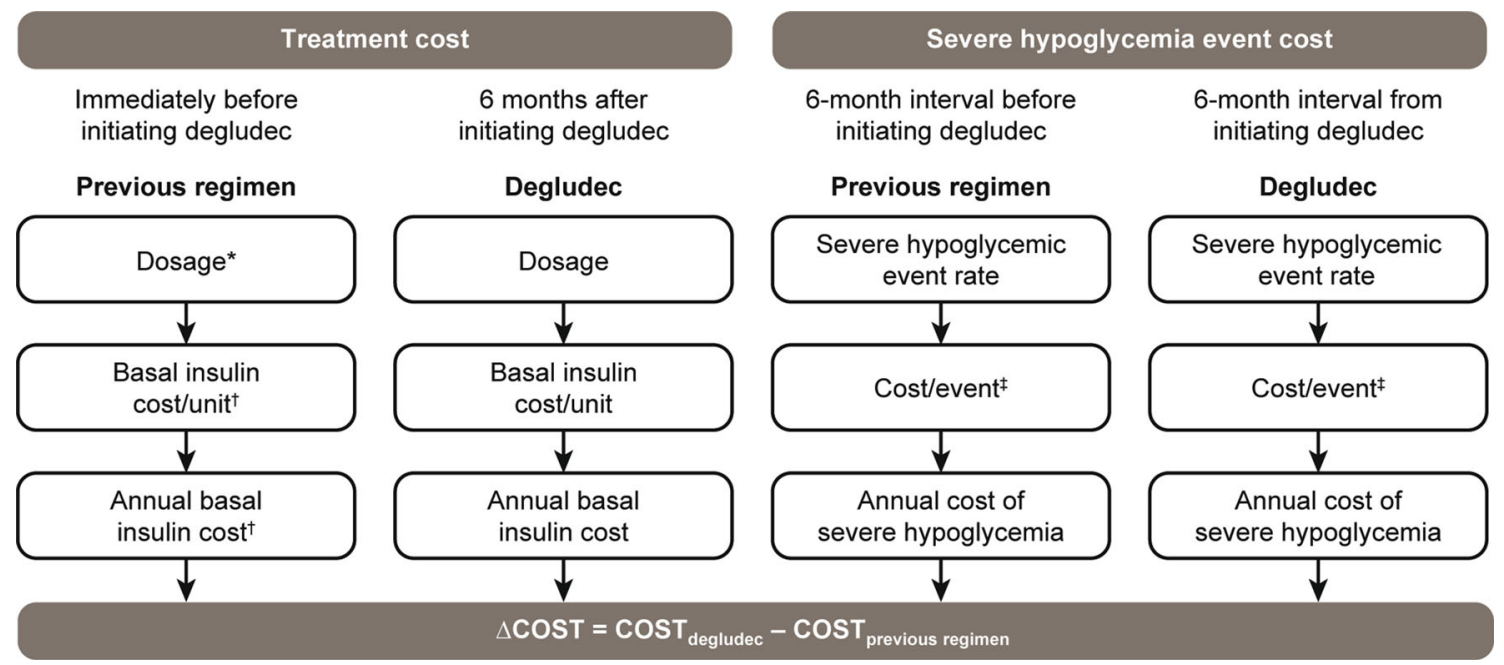

Fig. 2 Overview of the cost-effectiveness model for switching to degludec from other basal insulins. Previous regimens included basal-bolus therapy and biphasic insulin. Dosage was the mean basal insulin dose. Severe hypoglycemia was defined as an event requiring an ambulance call-out for the purposes of this analysis. Asterisk indicates that two

Table 1 Baseline characteristics of the patients enrolled in the study

\begin{tabular}{ll}
\hline Characteristic & Baseline value \\
\hline Number of patients & 42 \\
Mean age, years $( \pm \mathrm{SD})$ & $50.4( \pm 14.0)$ \\
Range, years & $22-80$ \\
Female/male (\%) & $64.3 / 35.7$ \\
Duration of diabetes, years $( \pm \mathrm{SD})$ & $26.1( \pm 12.2)$ \\
Range (years) & $4-48$ \\
HbA 1 , \% ( \pm SD) [mmol/mol] & $8.7( \pm 1.3)[72(14)]$ \\
Range, \% [mmol/mol] & $5.9-12.2[41-110]$ \\
Mean basal insulin dose & $36.8(29.4)$ \\
pre-switch (U) & $6-150$ \\
Range (U) & \\
Mean degludec starting dose (U) & $29.2(23.7)$ \\
Range (U) & $4-120$ \\
\hline
\end{tabular}

$H b A_{1 c}$ glycated hemoglobin, SD standard deviation, $U$ units patients who received biphasic insulin before initiating degludec were included; dagger symbol indicates that the costs were calculated for glargine 100 units $/ \mathrm{mL}$; double dagger symbol indicates the direct cost of an episode (excluding ambulance call-out and/or hospital admission) for Birmingham and the surrounding area

reduced significantly from 30.0 (14.7-45.0 units to 25.5 (14.0-30.2) units; $p<0.0001$. For the 39 patients previously on another basal-bolus regimen, data on insulin (carbohydrate ratios, type, and average dose of bolus) were available for 31 of them. Of these, only one patient's insulin:carbohydrate ratio had increased at follow-up; eight reduced and 22 did not change.

Two patients experienced an episode of DKA in the 6 months before degludec initiation; there were no DKA events in the 6 months after degludec initiation. There were eight episodes of severe hypoglycemia in the 6 months before degludec initiation, and two episodes in the 6-month follow-up period.

All patients completed the Clarke Hypoglycemia Questionnaire (Table 2) and the Patient Satisfaction Questionnaire (Table 3). The percentage of patients who reported experiencing more than two episodes of moderate hypoglycemia in the past 6 months decreased from $31 \%$ before to $8 \%$ after degludec initiation. No patients reported worsening treatment satisfaction after switching to degludec. 


\section{Cost-Effectiveness}

Before switching to degludec, the majority of patients $(n=22)$ were taking glargine U100, which is therefore taken as an illustrative example with which to assess the potential cost impact of switching to degludec. After taking into account the average daily basal insulin dose for patients immediately before switching to degludec and the local product costs at the time of study, the average annual costs per patient for glargine U100 and degludec in patients with T1D with problematic hypoglycemia were estimated to be $£ 376.10$ and $£ 336.51$, respectively [22].

The estimated direct cost (excluding ambulance call-out and/or hospital admission) of an episode of severe hypoglycemia in patients with T1D in the greater Birmingham and surrounding area was taken as $£ 189.20$ [1]. Based on these data, it was estimated that the annual total direct cost of severe hypoglycemia per patient was $£ 72.08$ and $£ 19.92$ before and after switching to degludec. Taking into account the reduced basal dose and reduced number of severe hypoglycemic events, it is conservatively estimated that for this cohort of patients, switching to degludec saved at least $£ 91.75$ per patient per year (based on the 2016 treatment costs for degludec and glargine U100).

\section{DISCUSSION}

In patients with T1D and problematic hypoglycemia, switching basal insulin to degludec resulted in a significant reduction in both $\mathrm{HbA}_{1 \mathrm{c}}$ and total basal insulin dose without a corresponding increase in bolus dose. There were also reductions in the number of episodes of DKA and moderate and severe hypoglycemia.

Insulin therapy is required to control BG levels in patients with T1D, but is associated with hypoglycemia, the major barrier to insulin titration and optimal glycemic control [23]. Advanced age, longer diabetes duration and lower $\mathrm{HbA}_{1 \mathrm{c}}$ have all been associated with an increased risk of hypoglycemia in patients with diabetes $[24,25]$. The phase 3b SWITCH 1 trial

Table 2 Results from the Clarke Hypoglycemia Questionnaire

\begin{tabular}{lcc}
\hline Question & Number of patients $(\%)$ & \\
\cline { 2 - 3 } & $\mathbf{6}$ months before degludec initiation & $\mathbf{6}$ months after degludec initiation \\
\hline How often patients experienced moderate hypoglycemia & $33(77)$ \\
Never & $13(31)$ & $6(15)$ \\
Once or twice & $16(38)$ & $3(8)$ \\
More than twice & $13(31)$ & \\
Lowest blood glucose range in which symptoms were experienced & $25(59)$ \\
$59.5-68.5 \mathrm{mg} / \mathrm{dL}(3.3-3.8 \mathrm{mmol} / \mathrm{L})$ & $17(41)$ & $11(25)$ \\
$50.5-57.7 \mathrm{mg} / \mathrm{dL}(2.8-3.2 \mathrm{mmol} / \mathrm{L})$ & $11(25)$ & $6(16)$ \\
$<50.5 \mathrm{mg} / \mathrm{dL}(<2.8 \mathrm{mmol} / \mathrm{L})$ & $14(34)$ & $3(8)$ \\
Extent that hypoglycemia could be predicted by symptoms & $6(15)$ \\
Rarely & $20(46)$ & $10(23)$ \\
Sometimes & $6(15)$ & $23(54)$ \\
Often & $3(8)$ & \\
Always & $13(31)$ & \\
\hline
\end{tabular}


Table 3 Results from the Patient Satisfaction Questionnaire

\begin{tabular}{ll}
\hline Question & $\begin{array}{l}\text { Number of patients } \\
\text { (percentage) } 6 \text { months } \\
\text { after degludec initiation }\end{array}$ \\
\hline
\end{tabular}

Fear of hypoglycemia

$\begin{array}{lc}\text { Worse } & 0(0) \\ \text { No change } & 9(21) \\ \text { Improved } & 26(62) \\ \text { Much improved } & 7(17) \\ \text { Confidence in efficacy of treatment } \\ \text { Worse } & 0(0) \\ \text { No change } & 3(7) \\ \text { Improved } & 38(91) \\ \text { Much improved } & 1(2)\end{array}$

Predictability of blood glucose readings

$\begin{array}{lc}\text { Worse } & 0(0) \\ \text { No change } & 6(14) \\ \text { Improved } & 34(81) \\ \text { Much improved } & 2(5) \\ \text { Concerns about diabetes } & \\ \text { Worse } & 0(0) \\ \text { No change } & 7(17) \\ \text { Improved } & 30(71) \\ \text { Much improved } & 5(12)\end{array}$

Treatment satisfaction

$\begin{array}{lc}\text { Worse } & 0(0) \\ \text { No change } & 3(7) \\ \text { Improved } & 32(76) \\ \text { Much improved } & 7(17)\end{array}$

Would like to continue treatment
Yes
$41(98)$
No
$1(2)$

(NCT02034513) enrolled patients with T1D who had at least one hypoglycemia risk factor (e.g. a T1D duration of more than 15 years), and showed significantly lower rates of hypoglycemia with degludec compared with glargine U100 at equivalent $\mathrm{HbA}_{1 \mathrm{c}}$, with the benefit being relatively greater in magnitude than in the earlier phase $3 a$ studies $[12,26]$. We therefore anticipated that degludec would have greater benefits in patients particularly prone to hypoglycemia, and our results show that not only is the risk of hypoglycemia reduced in such patients, but there is also an improvement in glycemic control without an increase in insulin dose for the majority of patients.

Frequent episodes of hypoglycemia can lead to hypoglycemia unawareness, which is associated with altered counter-regulation and is more common in older patients with a long duration of diabetes [27]. In this prospective quality-improvement project, patients reported an improvement in recognizing symptoms of hypoglycemia, with more patients experiencing symptoms at higher BG levels [59.5-68.5 mg/dL (3.3-3.8 mmol/L)] after switching to degludec versus $<59.5 \mathrm{mg} / \mathrm{dL} \quad(<3.3 \mathrm{mmol} / \mathrm{L})$ before switching. This is likely a result of the reduced incidence of hypoglycemia with degludec, since recurrent episodes can lead to impaired glucose counter-regulation and reduced hypoglycemia awareness [28]. In turn, impaired hypoglycemia awareness increases the risk of severe episodes between three- and fivefold [29, 30]. However, the normal hierarchy of hypoglycemia symptom recognition before cognitive dysfunction can be restored in patients if hypoglycemia is avoided [31].

In addition, we report that degludec treatment was associated with a reduced fear of hypoglycemia. Long-term effects of hypoglycemia can include behavioral changes as well as a significant anxiety or fear of future events [4]. Fear of hypoglycemia can adversely affect diabetes management and clinical outcomes through reduced adherence to medications or a reluctance of physicians to titrate insulin more aggressively $[32,33]$. It is common for patients to maintain elevated BG levels because of a fear of hypoglycemia [34]; thus, reducing this fear may have contributed to the improved $\mathrm{HbA}_{1 \mathrm{c}}$ 
levels observed in this study. Furthermore, both hypoglycemia unawareness and recurrent severe hypoglycemia can lead to a fear of hypoglycemia, which in turn can reduce adherence to therapeutic decisions [35]. Thus, the clinical benefits of switching to degludec may also contribute to improved well-being and treatment adherence. Degludec was also associated with an improvement in diabetes-related QoL. Six months after starting degludec treatment, 41 of the 42 patients in this study said they would prefer to continue this treatment. Overall, degludec was found to be well tolerated, BG values were seen as more predictable compared with other basal insulins, confidence in the treatment was high, and diabetes-related concerns were reduced.

Newer, long-acting insulin analogs offer the advantage of flexibility, once-daily dosing, and less risk of hypoglycemia compared with older, cheaper human insulin analogues such as neutral protamine Hagedorn insulin [36, 37]. Basal insulin unit costs vary between the newer, longacting basal insulins, hence comparative health economic analyses of treatments can help healthcare payers to make decisions about how to efficiently allocate resources to achieve maximum healthcare gains within the constraints of a limited budget. In our illustrative costs analysis, switching to degludec from other basal insulins was estimated to achieve substantial cost savings in this cohort of patients, despite the higher cost of degludec, due to reductions in the frequency of severe hypoglycemic events and the basal insulin dose after switching to degludec. Moreover, the estimated average costs of an ambulance call-out and a hospital admission due to hypoglycemia in the greater Birmingham and surrounding area were $£ 242.78$ and $£ 990.96$, respectively, according to recent data at the time of this study [2, 3]. Additionally, avoiding an episode of DKA in the UK had an estimated associated cost saving of between $£ 1000.00$ and $£ 1400.00$ [38]. Hence, our analysis represents a conservative estimate of cost savings with degludec, as we excluded direct costs associated with ambulance call-outs and hospital admissions for hypoglycemia in our estimation of treatment costs.
Limitations of this study include the small sample size and the variability in baseline $\mathrm{HbA}_{1 \mathrm{c}}$, which ranged from 5.9 to $12.2 \%$ (41-110 $\mathrm{mmol} / \mathrm{mol})$. Another limitation was the fact that patient recall and diaries were relied upon as a data source for the pre-switch 6-month interval. The study also combined data from patients on different insulin regimens and although the most commonly used insulin was glargine U100, there were 17 patients who had received insulin detemir prior to switching. The cost impact assessment was based on the glargine U100 acquisition price, which, per unit, is similar to that of insulin detemir. It is possible, however, that baseline differences between these insulins (e.g. dose discrepancies [39]) confound this analysis, which should therefore be viewed as illustrative only. On the other hand, this study shows clear benefits in terms of both improved glycemic control and tolerability from switching to degludec in a selected patient group, and it helps to redress the lack of real-world data on the effect of degludec treatment in patients with recurrent, problematic hypoglycemia or hypoglycemia unawareness.

\section{CONCLUSIONS}

The results of this real-world study indicate that degludec may be a beneficial treatment for patients with T1D with problematic hypoglycemia. In such patients, the switch to degludec resulted in a reduced basal dose, reduced $\mathrm{HbA}_{1 \mathrm{c}}$ levels, improved QoL, and reduced rates of DKA and hypoglycemia. Used in appropriate targeted patients, degludec could therefore lead to significant cost savings for the NHS, despite its acquisition cost.

\section{ACKNOWLEDGEMENTS}

Funding. This manuscript was supported by a grant from Novo Nordisk in respect of article processing charges and medical writing costs. Novo Nordisk has not influenced the content of the publication nor been involved in the study design, data collection, analysis or reporting. All 
authors had full access to all of the data in this study and take complete responsibility for the integrity of the data and accuracy of the data analysis.

\section{Medical Writing, Editorial and Other} Assistance. Medical writing and submission support were provided by Katie Greenfield, Anna Campbell, Germanicus Hansa-Wilkinson and Daria Renshaw of Watermeadow Medical, an Ashfield company, part of UDG Healthcare plc. Support for this assistance was funded by Novo Nordisk.

Authorship. All named authors meet the International Committee of Medical Journal Editors (ICMJE) criteria for authorship for this manuscript, take responsibility for the integrity of the work as a whole, and have given final approval to the version to be published.

Prior Presentation. Data from this study were presented as a poster (Dar, Brewer and Karamat) at Diabetes UK, March 2015, London, UK.

Disclosures. Muhammad A. Karamat has received honoraria for lectures and advisory work or support for attending conferences from Boehringer Ingelheim, AstraZeneca, Roche, Eli Lilly, Novo Nordisk, Janssen, and Sanofi-Aventis. He has received a project grant from the Sanofi-Aventis Excellence in Diabetes program outside the submitted work. Shujah Dar has no conflicts of interest to declare. Srikanth Bellary received research grants from Novo Nordisk UK Ltd while the project was being conducted. He has also received a research grant from The Binding Site Ltd, speaker fees from AstraZeneca, speaker fees and educational support from Boehringer Ingelheim, and speaker fees from MSD, Janssen, Eli Lilly, and Sanofi-Aventis outside the submitted work. Abd A. Tahrani is a clinician scientist supported by the National Institute for Health Research (NIHR) in the UK. $\mathrm{He}$ has received honoraria for lectures and advisory work or support for attending conferences from Boehringer Ingelheim, Bristol-Myers Squibb, Eli Lilly, Novo Nordisk, Janssen, and Sanofi-Aventis. He has also received investigator-led grant support from the Novo Nordisk Research Foundation. The views expressed in this publication are those of the author(s) and not necessarily those of the National Health Service, the NIHR, or the Department of Health.

Compliance with Ethics Guidelines. This article is based on previously conducted studies and does not contain any studies with human participants or animals performed by any of the authors.

Data Availability. The datasets generated during and/or analyzed during the current study are available from the corresponding author on reasonable request.

Open Access. This article is distributed under the terms of the Creative Commons Attribution-NonCommercial 4.0 International License (http://creativecommons.org/licenses/ by-nc/4.0/), which permits any noncommercial use, distribution, and reproduction in any medium, provided you give appropriate credit to the original author(s) and the source, provide a link to the Creative Commons license, and indicate if changes were made.

\section{REFERENCES}

1. Department of Health. Ambulance services: see and treat and convey (ASSO2). In: NHS reference costs 2013-14. London: Department of Health; 2014.

2. Department of Health. KB01A: diabetes with hypoglycaemic disorders 70 years and over (nonelective spell tariff); KB01B: diabetes with hypoglycaemic disorders 69 years and under (non-elective spell tariff). In: Payment by results tariff information spreadsheet for 2013 to 2014. London: Department of Health; 2014.

3. Department of Health. A\&E: category 1 investigation with category 1-2 treatment (VB09Z). In: Payment by results tariff information spreadsheet for 2013 to 2014. London: Department of Health; 2014.

4. Fidler C, Elmelund CT, Gillard S. Hypoglycemia: an overview of fear of hypoglycemia, quality-of-life, and impact on costs. J Med Econ. 2011;14:646-55. 
5. Johnston SS, Conner C, Aagren M, Ruiz K, Bouchard J. Association between hypoglycaemic events and fall-related fractures in Medicare-covered patients with type 2 diabetes. Diabetes Obes Metab. 2012;14:634-43.

6. Goto A, Arah OA, Goto M, Terauchi Y, Noda M. Severe hypoglycaemia and cardiovascular disease: systematic review and meta-analysis with bias analysis. BMJ. 2013;347:f4533.

7. Zoungas S, Patel A, Chalmers J, et al. Severe hypoglycemia and risks of vascular events and death. N Engl J Med. 2010;363:1410-8.

8. Whitmer RA, Karter AJ, Yaffe K, Quesenberry CP Jr, Selby JV. Hypoglycemic episodes and risk of dementia in older patients with type 2 diabetes mellitus. JAMA. 2009;301:1565-72.

9. Heise T, Hermanski L, Nosek L, Feldman A, Rasmussen S, Haahr H. Insulin degludec: four times lower pharmacodynamic variability than insulin glargine under steady-state conditions in type 1 diabetes. Diabetes Obes Metab. 2012;14:859-64.

10. Heise T, Nosek L, Bottcher SG, Hastrup H, Haahr H. Ultra-long-acting insulin degludec has a flat and stable glucose-lowering effect in type 2 diabetes. Diabetes Obes Metab. 2012;14:944-50.

11. Lane WS, Bailey TS, Gerety G, et al. SWITCH 1: reduced hypoglycemia with insulin degludec (IDeg) vs. insulin glargine (IGlar), both U100, in patients with T1D at high risk of hypoglycemia: a randomized, double-blind, crossover trial. Diabetes. 2016;65(Suppl 1A):Abst:87-LB.

12. Ratner R, Gough SC, Mathieu C, et al. Hypoglycaemia risk with insulin degludec compared with insulin glargine in type 2 and type 1 diabetes: a preplanned meta-analysis of phase 3 trials. Diabetes Obes Metab. 2013;15:175-84.

13. Wysham C, Bhargava A, Chaykin L, et al. Effect of insulin degludec vs insulin glargine U100 on hypoglycemia in patients with type 2 diabetes: the SWITCH 2 randomized clinical trial. JAMA. 2017;318:45-56.

14. Freemantle N, Evans M, Christensen T, Wolden ML, Bjorner JB. A comparison of health-related quality of life (health utility) between insulin degludec and insulin glargine: a meta-analysis of phase 3 trials. Diabetes Obes Metab. 2013;15:564-71.

15. Sherman RE, Anderson SA, Dal Pan GJ, et al. Realworld evidence-what is it and what can it tell us? N Engl J Med. 2016;375:2293-7.

16. Siegmund T, Tentolouris N, Knudsen ST, et al. A European, multicentre, retrospective, non- interventional study (EU-TREAT) of the effectiveness of insulin degludec after switching basal insulin in a population with type 1 or type 2 diabetes. Diabetes Obes Metab. 2018;20:689-97.

17. Landstedt-Hallin L. Changes in HbA1c, insulin dose and incidence of hypoglycemia in patients with type 1 diabetes after switching to insulin degludec in an outpatient setting: an observational study. Curr Med Res Opin. 2015;31:1487-93.

18. Evans M, McEwan P, Foos V. Insulin degludec early clinical experience: does the promise from the clinical trials translate into clinical practice-a casebased evaluation. J Med Econ. 2015;18:96-105.

19. Evans M, Chubb B, Gundgaard J. Cost-effectiveness of insulin degludec versus insulin glargine in adults with type 1 and type 2 diabetes mellitus. Diabetes Ther. 2017;8:275-91.

20. Clarke WL, Cox DJ, Gonder-Frederick LA, Julian D, Schlundt D, Polonsky W. Reduced awareness of hypoglycemia in adults with IDDM. A prospective study of hypoglycemic frequency and associated symptoms. Diabetes Care. 1995;18:517-22.

21. MIMS. MIMS Monthly Index of Medical Specialities. 2017. https://www.mims.co.uk/. Accessed Dec 2016.

22. Novo Nordisk. Summary report for the Tresiba ${ }^{\circledR}$ (insulin degludec) cost comparison model. Bagsværd: Novo Nordisk; 2016.

23. Cryer PE. Hypoglycaemia: the limiting factor in the glycaemic management of type I and type II diabetes. Diabetologia. 2002;45:937-48.

24. The Diabetes Control and Complications Trial Research Group. The effect of intensive treatment of diabetes on the development and progression of long-term complications in insulin-dependent diabetes mellitus. The Diabetes Control and Complications Trial Research Group. N Engl J Med. 1993;329:977-86.

25. Huang ES, Liu JY, Moffet HH, John PM, Karter AJ. Glycemic control, complications, and death in older diabetic patients: the diabetes and aging study. Diabetes Care. 2011;34:1329-36.

26. Heller S, Buse J, Fisher M, et al. Insulin degludec, an ultra-longacting basal insulin, versus insulin glargine in basal-bolus treatment with mealtime insulin aspart in type 1 diabetes (BEGIN Basal-Bolus Type $1)$ : a phase 3 , randomised, open-label, treat-to-target non-inferiority trial. Lancet. 2012;379:1489-97.

27. Bremer JP, Jauch-Chara K, Hallschmid M, Schmid S, Schultes B. Hypoglycemia unawareness in older 
compared with middle-aged patients with type 2 diabetes. Diabetes Care. 2009;32:1513-7.

28. Hayes M. Management of hypoglycaemia unawareness in type 1 diabetes: a review. J Diabetes Nurs. 2008;12:234-8.

29. Geddes J, Schopman JE, Zammitt NN, Frier BM. Prevalence of impaired awareness of hypoglycaemia in adults with type 1 diabetes. Diabet Med. 2008;25:501-4.

30. Choudhary P, Geddes J, Freeman JV, Emery CJ, Heller SR, Frier BM. Frequency of biochemical hypoglycaemia in adults with type 1 diabetes with and without impaired awareness of hypoglycaemia: no identifiable differences using continuous glucose monitoring. Diabet Med. 2010;27:666-72.

31. Cranston I, Lomas J, Maran A, Macdonald I, Amiel SA. Restoration of hypoglycaemia awareness in patients with long-duration insulin-dependent diabetes. Lancet. 1994;344:283-7.

32. Peyrot M, Barnett AH, Meneghini LF, SchummDraeger PM. Insulin adherence behaviours and barriers in the multinational Global Attitudes of Patients and Physicians in Insulin Therapy study. Diabet Med. 2012;29:682-9.

33. Leiter LA, Yale JF, Chiasson J-L, Harris SB, Kleinstiver P, Sauriol L. Assessment of the impact of fear of hypoglycemic episodes on glycemic and hypoglycemic management. Can J Diabetes. 2005;29:186-92.

34. Wild D, Von MR, Brohan E, Christensen T, Clauson $\mathrm{P}$, Gonder-Frederick L. A critical review of the literature on fear of hypoglycemia in diabetes: implications for diabetes management and patient education. Patient Educ Couns. 2007;68:10-5.

35. Smith CB, Choudhary P, Pernet A, Hopkins D, Amiel SA. Hypoglycemia unawareness is associated with reduced adherence to therapeutic decisions in patients with type 1 diabetes: evidence from a clinical audit. Diabetes Care. 2009;32:1196-8.

36. Heise $\mathrm{T}$, Nosek L, Ronn BB, et al. Lower withinsubject variability of insulin detemir in comparison to NPH insulin and insulin glargine in people with type 1 diabetes. Diabetes. 2004;53:1614-20.

37. Vague P, Selam JL, Skeie $S$, et al. Insulin detemir is associated with more predictable glycemic control and reduced risk of hypoglycemia than NPH insulin in patients with type 1 diabetes on a basal-bolus regimen with premeal insulin aspart. Diabetes Care. 2003;26:590-6.

38. National Institute for Health and Care Excellence. Costing statement: diabetes in children and young people. Implementing the NICE guideline on diabetes (type 1 and type 2 ) in children and young people (NG18). 2015. https://www.nice.org.uk/ guidance/ng18/resources/costing-statement436711789. Accessed 10 Jul 2017.

39. Wallace JP, Wallace JL, McFarland MS. Comparing dosing of basal insulin analogues detemir and glargine: is it really unit-per-unit and dose-perdose? Ann Pharmacother. 2014;48:361-8. 